\title{
Atatürk, Cumhuriyet ve Çocuk Ruhu
}

\section{Doç. Dr. Emel KOÇ*}

\begin{abstract}
"Küçük hanımlar, küçük beyler! Sizler hepiniz âtinin bir gülü, yıldızı, bir nur-i ikbalisiniz. Memleketi asıl nura gark edecek sizsiniz. Kendinizin ne kadar mühim, kıymetli olduğunuzu düşünerek ona göre çalışını. Sizlerden çok şeyler bekliyoruz; klzlar, çocuklar!”
\end{abstract}

\section{$\ddot{O}_{z e t}$}

Çocukluk kavramı tarihsel, kültürel ve felsefi açıdan bazı belirsizlikler içermiş olsa da, çocuk denildiğinde zihnimizde meraklılık, yaratıcılık, yeniliklere açık olma, bă̆ımsızlık gibi nitelikler çağrışım yapmaktadır. Çocuklar, böyle gelmiş böyle gider düşüncesine bă̆ll kalmadan düşünebilme yeteneğine sahiptirler. Bu nitelikler göz. önünde bulunduruldu ğunda çocukluk biyolojik olarak yaşamın bir döneminde yaşanıp yitirilen bir dönem olmanın ötesinde bir anlama da sahiptir. Biyolojik çocukluk kadar ruhun çocukluğu da önemlidir. Ruhun çocukluğu özgürlük ve bă̆ımsızlık ister. Bu sebeple çocukluk bir karakter biçimi olup, yeniliğin, dönüşümün yılmadan ardından koşabilme her dem taze kalabilme, olgunluğu çocuk ruhuyla yoğurabilme anlamlarına da gelir. Atatürk'ün Cumhuriyete kazandırmaya çalıştı̆̆ r ruh, böyle araştırıcı, yaratıcı bir çocuk ruhudur. Cumhuriyet ruhu bilim, sanat ve düşünce alanında özgün ve yaratıcı ürünler ortaya koyan ve koyması gereken olgun bir çocuk ruhudur. Bu sebeple Atatürk’ün ulusal egemenliği çocuk bayramıyla birleştirmesi ve milli egemenlik kavramıla milletin geleceğini temsil eden çocuk kavramını birbirine bağlaması O'nun dehasının bir göstergesidir.

Anahtar Kelimeler: Çocukluk, egemenlik, yaratıcılı, e ğitim, kültür.

*Gazi Üniversitesi, Gazi Eğitim Fakültesi, Felsefe Grubu Eğitimi Anabilim Dalı. E-Mail: emelkoc20@yahoo.com 


\section{Ataturk, Republic and the Spirit of Child}

\section{ABSTRACT}

Although the concept of 'childhood' incorporates some ambiguity with regards to history, culture and philosophy, the word 'kid' always evokes curiosity, creativity, being open to new things and independence. Children are capable of thinking without the boundaries of conventional thinking like 'it was always like this, it should go on like this'. Given this fact, childhood is more than something that is lived in one period of life and then ends and fades. The childhood of the spirit is as important as the childhood of the biological body. A child spirit demands freedom and independence. Therefore, childhood is a way of character and refers to chasing new things, change without ever giving up, being capable of staying fresh, and combining maturity with a spirit of a child. The spirit that Atatürk strived to gain for the Republic was such a spirit of a child, which is innovative and likes to explore. The spirit of the Republic is a mature spirit of a child that produces and has to produce unique and innovative works in science, art and philosophy. Therefore combination of the national sovereignty with the festival for kids as well as using together the concept of national sovereignty with the concept of a child that represents future of a nation by Atatürk is a sheer proof of his genius.

Key Words: Childhood, sovereignty, creativity, education, culture.

Çocuk olmak ne anlama gelir? Çocukların düşüncelerini yetişkinlerden ayıran nedir? Çocuklar birer küçük insan mıdır? tarzındaki sorular ilk bakışta çok sıradanmış gibi görünse de, bu sorulara yanıt aramaya çalışıldığında çocukluk kavramının tarihsel, kültürel ve felsefi anlamda bazı belirsizlikler içerdiği görülür.

Çocukluk kavramı tarihsel olarak belirsizlikler içerir. Zira erken dönemlerde çocukların, büyüklerden daha az yemek yiyen, daha az çalışan küçük insan olarak tanımlanmış olduğu görülmektedir. Ama öte yandan onlar küçük niteliğine rağmen kendilerine verilebilen görev türleri, düşünce ya da davranış biçimleri yönünden sanki büyüklerden pek de farklı bir şekilde değerlendirilmemiş gibidirler. ${ }^{1}$

Çocukluk kavramı, kültürel anlamda da açıklanması güç bir kavramdır. Çünkü söz konusu kavram, her kültür tarafından aynı şekilde anlaşılmış değildir. Örneğin, Margaret Mead, Pasifik adalarında hikâyelerin çocuklar için değil, büyükler için anlatıldığı, çocukluğun hayal dünyasından uzak, gerçekçi ve yavan geçirilmesi gereken bir dönem olduğu bir kültürden söz etmektedir. Nihayet çocukluk kavramı, felsefi anlamda da belirsizlikler içermektedir. Zira çocuk ve yetişkin arasında ne tür bir fark olduğu

\footnotetext{
${ }^{1}$ Gareth B. Matthews, Çocukluk Felsefesi, İstanbul, 2000, s.15.
} 
yönündeki sorular kendi içerisinde felsefi problemler ihtiva etmektedir. ${ }^{2}$ Çocukluğun ne olduğunu anlamamıza imkan veren en basit teori, çocuk/küçük insan teorisi olarak ifade edilebilecek olan teoridir. Bu teoriye göre, çocuk, yetişkinlerle olan yaş farkı sebebiyle 'ufak bir insan' olarak görülmektedir. Bu yaklaşım çocuk gelişiminin yalnızca bir büyüme süreci olduğunu düşündüğümüzde kabullenebileceğimiz bir yaklaşımdır. Oysaki çocukluğu, yalnızca büyüme dahilindeki gelişimi içeren bir anlayış çerçevesinde açıklamak tatmin edici değildir. Çünkü çocukluk, bu türden bir açıklama ile yetinilemeyecek kadar karmaşık olan zihinsel, duygusal ve sosyal gelişim açısından da değerlendirilmesi gereken bir dönemdir.

Aydınlanma çağı olarak nitelendirilen XVIII.y.y.'ın başlarında bile John Calvin'in etkisiyle çocukluğun olabildiğince çabuk aşılması gereken kötü bir dönem olduğu, özellikle küçük çocukların kirli, gürültüicü, yaramaz ve kötülük ile tembelliğe eğilimli oldukları düşünülüyordu. Geleneksel görüşte iyi çocuk, olabildiğince yetişkine benzeyen çocuk olup, itaatkar, sessiz ve kurallara saygılı küçük bir yetişkin olarak kabul ediliyordu. Oysaki bir eğitim reformcusu olan J.J. Rousseau, çocukluğu insan gelişiminin en doğal evresi olarak nitelendirmekte ve hızlı geçen bir çocukluk dönemini reddederek, çocukluğun insanın gelişimi ve zenginleşmesi adına önemli bir dönem olduğunu vurgulamaktadır. Çocuğu masum bir varlık olarak gören ${ }^{3}$ Rousseau'ya göre, Yaradan'in elinden çıkan her şey iyidir. Sonradan insanların elinde bozulur. Çocuk; hekim, asker, papaz olmadan önce insan olmalıdir. ${ }^{4}$

Cocukluk kavramı içinde belirsizlikler barındırmasına rağmen, çocuk olmak denildiğinde zihnimizde meraklılık, yaratıcılık, tazelik, heveslilik, inatçılık, yeniliklere açık olma, bağımsızlık, hayal gücü genişliği gibi nitelikler çağrışım yapmaktadır.

Yaşamlarının ilk beş yılı boyunca bağımsız bir insan olmak için mücadele veren çocuklar, ${ }^{5}$ çoğu zaman bir yetişkini kıskandıracak ölçüde hayal gücü, sorgulama ve yaratıcılık kapasitesine sahiptirler.

Onlar, alışkanlık, gelenek, görenek ve kurallardan uzak, bir şeyin nasıl olması gerektiği düşüncesinden bağımsız, böyle gelmiş böyle gider baskısına boyun eğmeden düşünebilme ve düşündüklerinde 1srar edebilme, 1srar ettiklerini uygulayabilme yeteneğine sahiptirler. ${ }^{6}$

\footnotetext{
${ }^{2}$ Matthews, a.g.e, s.15.

${ }^{3}$ Gerald L. Gutek, Ĕ̆gitime Felsefi ve İdeolojik Yaklașımlar, Ankara, 2001, s.79.

${ }^{4}$ Necdet Sakaoğlu, Osmanlı'dan Günümüze Eğitim Tarihi, İstanbul, 2003, s.49. 2002, s.2.

Jerry Wyckoff vd., Bağırıp Cağırmadan ya da Dövmeden Çocuk Terbiyesi, Ankara,

${ }^{6}$ Yüksel Özden, Ö̆rrenme ve Öğretme, Ankara, 2000, s.128.
} 
$\mathrm{Bu}$ sebeple çocuklar, yetişkinlerle kıyaslandıkları vakit çoğu zaman daha az disiplinli ve daha az ciddi olarak görünseler de, iş soru sormaya, sorgulamaya gelince sıradan bir meraktan fazlasını içeren-Evren nasıl başladı? Zaman nedir? gibi-sorular sorabildikleri görülür. İşte bu nedenle çocukluk, çocuk olabilmek; çocuk niteliklerine ve yaratıcılığına sahip olmak önemlidir. Çocuktaki aktivite ve yaratıcılığı fark eden Alman filozofu F. Nietzsche, felsefesinde çocuğa üst insan olabilme yolunda özel bir önem atfeder.

Nietzsche, felsefesinde yırtıcı hayvan, sürü insanı, özgür insan ve üst insan olmak üzere dört insan tipinden söz eder. Nietzsche'ye göre ilk iki tip, insan gelişiminin alt seviyelerini oluşturur. Orta ve vasat olanı değerli bulan sürü insanından, Nietzsche'nin geleceğin kanun koyucusu olarak söz ettiği, yeni değerlerin yaratıcısı olan üst insana doğru yol alabilmek ve özgürleşebilmek için katedilmesi gereken çetin bir yol vardır. Zira üst insan olma yolunda atılması gereken ilk adım, mevcut yaşam biçimleri ve değerlerinin sorgulanması ve değerlendirilmesidir.

Nietzsche, Böyle Buyurdu Zerdüşt adlı yapıtında üst insana giden yolda ruhun üç katarsis aşamasından söz eder. Ruhun üç biçim değişiminden (metamorphose) bahsederek ruhun nasıl deve, devenin aslan, aslanın da en sonunda çocuk olduğunu anlatır. ${ }^{7}$ Deve, organizmaya yabancı olan unsurları, ağır yükü simgelerken; aslan ise ruhun özgürleşmesini ifade eder. Aslandan sonra çocuk aşamasına geçilir. Çocuk, üst insan olmanın başlangıcıdır. Zira Nietzsche'ye göre, çocuk masumiyet ve unutuştur, yeni bir başlangıç, bir oyun, kendiliğinden dönen bir tekerlek ve bir ilk devinimdir. ${ }^{8}$ Çocuk, oluş ve değişime açık ve onlarla uyum içinde olduğu için masumdur. O, alışılmış değerlendirme kalıplarından bağımsızdır. Kendi kendine dönen tekerlek gibi yaratıcı hayat gücü onun içinde saf bir biçimde hareket eder.

Nietzsche'nin ifadelerinden de anlaşılacağı üzere çocukluk, biyolojik olarak yaşamın bir döneminde yaşanıp yitirilen bir evre olmasının yanı sıra bir anlama da sahiptir. Biyolojik çocukluk kadar ruhun çocukluğu da önemlidir.

Ruhun çocukluğu ya da çocukluğa ulaşması özgürlük ve bağımsızlık ister. Zira ruh bağımsızlığına erişemeyenler, bağımlılığı alışkanlık haline getirenler çocuk olamazlar. Çocukluk bir karakter biçimidir ve o yeniliğin, dönüşümün yılmadan ardından koşabilme, meraklı, araştırıcı ve düş dünyası geniş olabilme, her dem taze ve yaratıcı kalabilme, başka bir deyişle olgunluğu çocuk ruhuyla yoğurabilme anlamlarına da gelir.'

\footnotetext{
${ }^{7}$ Friedrich Nietzsche, Böyle Buyurdu Zerdüşt, İstanbul, 1984, s.31.

${ }^{8}$ Nietzsche, a.g.e, s.32-33.

9 Ahmet İnam, "Atatürk ve Çocuk", MPM Anahtar, 2003, s.20.
} 
İşte Ulu Önder Atatürk'ün Cumhuriyete kazandırmaya çalıştı̆̆g ruh, Cumhuriyet ruhu böyle heyecanlı, meraklı, araştırıcı, yaratıcı bir çocuk ruhudur. Cumhuriyet ruhu, bilim, sanat ve düşünce alanında özgün ve yaratıcı ürünler ortaya koyan, yaşama kendi açısından bakabilme cesareti taşıyan olgun bir çocuk ruhudur. ${ }^{10} \mathrm{Bu}$ sebeple Ulu Önderin 23 Nisan'1 çocuklara armağan etmesi, Türkiye Cumhuriyetini gençlere emanet etmesi, onlara olan derin şefkatinin yanı sıra, onlara duyduğu güvenin de bir göstergesi olması açısından dikkate değerdir. Zira 23 Nisan'ın Milli Egemenlik Bayramının yanı sıra Çocuk Bayramı olarak da kutlanması çok anlamlıdır. Bu suretle milli egemenlik kavramı ile milletin yarınlarını, geleceğini yansıtan çocuk kavramı arasındaki ilişki de vurgulanmış olmaktadır. Geleceğimizi kime emanet edeceğini isabetle tayin eden Atatürk, çocukları ve gençleri önemsemiş ve onlara ilgi göstermiştir.

Osmanlı Devletinde Tanzimat'la birlikte çocuk terbiyesinin ayrı bir alan olduğunun ve ihtisas gerektirdiğinin farkına varılmıştır. Bu alanda çalışma yapanların başında Münif Paşa, Edhem İbrahim Paşa, Sadık Rıfat Paşa ve Ahmet Mithat Efendi gelmektedir. Ahmet Mithat Efendi, Osmanlı aydınlarının pedogoji anlayışını Avrupa ile karşılaştırarak farkı şöyle dile getirmiştir: "Avrupa'da çocuk, adam; Türkiye'de çocuk, çocuktur." ${ }^{11}$ Ulu Önder Atatürk'ün çocuklara yaklaşımı ise, Avrupalı pedagogların görüşleri doğrultusunda olmuş, çocukları bir büyük insan olarak kabul etmiş, onların, yanında içlerinden geldiği gibi konuşma ve davranmalarına izin vermiştir. Çocuklar, Ata'nın yanında düşüncelerini hiç çekinmeden açıkça ifade edebilmişlerdir. ${ }^{12}$

Sevdiklerine hangi yaşta olursa olsun çocuk diye seslenen Atatürk'e göre, çocuk öncelikle sevgi demektir. Ata'nın çocuklarda en hoşuna giden yan, saflıkları "ikiyüzlülük nedir bilmemeleri, bütün istek ve duygularını içlerinden geldiği gibi açıklamalarıdır."13

Ulu Önder çoğu ailede öteden beri gelen bir alışkanlık olduğunu, çocuklarını konuşturmadıklarını ve dinlemediklerini, bu tavrın ise son derece yanlış olduğunu belirterek, çocukların serbestçe konuşmaya, düşündüklerini, duyduklarını olduğu gibi ifade etmeye teşvik edilmeleri gerektiğini düşünür. Böylece hem hatalarını düzeltmeye imkan bulunur hem de ileride yalancı ve iki yüzlü olmalarının önüne geçilmiş olur. Kısacası çocuklarımızı artık düşüncelerini hiç çekinmeden açıkça söylemeye, içten inandıklarını savunmaya, buna karşılık da başkalarının samimi düşüncelerine saygı

\footnotetext{
${ }^{10}$ İnam, a.g.e, s.20.

${ }^{11}$ Cüneyt Okay, Osmanlı Çocuk Hayatında Yenileşmeler, İstanbul, 1998, s.51

${ }^{12}$ Hülya Şahin, "Atatürk'te Çocuk Sevgisi ve Atatürk Döneminde Çocuklara Yönelik Yapılan Calışmalar", Silahlı Kuvvetler Dergisi, 2000, s.234-235.

${ }^{13}$ Hasan R. Soyak, Doğumundan Ölümüne Kadar Atatürk ve Atatürk'ün Hususiyetleri, İstanbul, 1965 , s.79.
} 
göstermeye alıştırmalıyız. Aynı zamanda onlarda yurt, ulus, aile ve yurttaş sevgisiyle birlikte doğruya, iyiye ve güzele karşı sevgi ve ilgi uyandırılmaya çalışılmalıdır. ${ }^{14}$ Böylece Atatürk, çocuk eğitiminde ana kucağından başlayarak en yüksek eğitim ocaklarına değin her yer ve zamanda üzerinde durulacak hususların altını çizmiş, bu suretle çocuklarımızın memlekete yararlı birer vatandaş ve mükemmel birer insan olabileceğini belirtmiştir.

Bu hususlara Atatürk'ün manevi çocuklarının eğitiminde de bizzat özen gösterdiği anlaşılmaktadır. Atatürk'ün manevi çocuklarından olan Sabiha Gökçen, Ata'nın çocukların yetişmesinde dikkat ettiği hususları 11 Mart 1999 yılında kendisiyle yapılan bir röportajda şöyle belirtmiş̧tir: Yalan söylememeleri, dürüst ve ciddi olmaları, başkalarının özel hayatlarına karışmamaları, insanlarla olan ilişkilerinin saygı ve sevgiye dayanması. Çocuklara Avrupai tarzda bir eğitim verilmiş, onların modern bir toplumun bireyleri olarak yetişmelerine özen gösterilmiştir. Onlar giyinişleri, hal ve tavırları, özgürce fikirlerini ifade edebilmeleri, eğitim hayatında kaydettikleri başarıları ile yeni nesle emsal teşkil etmişlerdir. ${ }^{15}$ Atatürk'ün manevi çocuklarından Sabiha Gökçen ilk Türk kadın pilotu, Afet İnan ise ilk Türk kadın tarih profesörü olmuşlardır.

Atatürk için çocuk, vatan gibi sevilmesi, ulusun haklarını korur gibi korunması gereken bir varlıktır. Hatıra defteri onun cephede bulunduğu en bunalımlı günlerde bile çocuklarla yakından ilgilendiğini belirleyen bir belgedir. ${ }^{16}$ Atatürk'le karşılaşan çocukların adeta yaşamlarının akışı değişmiştir. Ulu Önder, çocuklar arasında zeki ve yetenekli olanlara yetenekleri doğrultusunda yetişebilmeleri için devlet desteği sağlamış, evlat edindiği manevi çocuklarının yanı sıra bazı çocukları himayesine alarak okumalarına imkan vermiştir.

Ata'nın kız kardeşi Makbule Atadan ve Sabiha Gökçen'in anıları başta olmak üzere yakın arkadaşlarının ifadelerine göre Atatürk'ün manevi çocukları ve himayesindeki çocukların isimleri şunlardır: Mustafa, Sadiye, Rukiye, Zehra, Abdürrahim, Nebile, İbrahim, Sabiha Gökçen, Afet İnan, Ülkü, İhsan, Ömer, Afife, Ayşe, Mahmude. Atatürk'ün vasiyetnamesinde ise, manevi çocuklarından Ülkü, Sabiha Gökçen ve Afet İnan'ın isimlerine rastlanmaktadır. ${ }^{17}$

Atatürk yurt gezileri sırasında okullara giderek dersleri izlemiş, öğrencilere sorular sormuş, eğitim uygulamalarının bizzat içinde yer almıştır.

\footnotetext{
${ }^{14}$ Soyak, a.g.e, s.78.

${ }^{15}$ Şahin, a.g.e, s.236

${ }^{16}$ Cemil Sönmez, Atatürk'te Çocuk Sevgisi, Ankara, 2004, s.2.

${ }^{17}$ Şahin, a.g.e, s.236.
} 
Atatürk, öğrenmeye ve öğretmeye meraklıdır. Zihninde ve gönlünde her zaman öğretmenlik eğilimi taşımıştır. Onun bu özelliği yazı, dil devrimi günlerinde iyice açığa çıkmıştır. Öğrencilerle konuşmak, sınavlarda bulunmak isteyen Atatürk, sınavlara girmiş hatta not verdiği de olmuştur. ${ }^{18}$

Yurt gezilerinde okul ziyaretlerinde bulunan Ulu Önder bir keresinde Edirne'de bir ilkokula gitmek istemişti. Atatürk okulun başöğretmenine "Bizi birinci sınıf dersliğine götürür müsünüz?" dedi. Başöğretmen, "Başüstüne Atam!" diyerek yol gösterdi. Sınıfta çocuklardan ikisi kara tahtada, öbürleri sıralarında "Atatürk çok yaşa" cümlesini yazıyorlardı. Çocuklar Atatürk'ü görür görmez, öğretmenin işaretini beklemeden ayağa kalktılar. Hepsinin gözleri pırıl pırıldı. Atatürk, çocukların yazdıklarına baktı, beğendi, çocukları okşadı. Sonra öğretmene "İzin verirseniz bir soru soracağım" diyerek, çocuklara, insanla hayvan arasında ne fark olduğunu sordu. Bunun üzerine bir çocuk ayağa kalkarak, 1şıl 1şıl gözlerle "Atam, insan şaha kalkmıştır, At da şaha kalkar ama her zaman değil” yanıtını verdi. Atatürk'ün gözleri çakmak çakmak olmuştu. Sınıftan çıkıp biraz yürüdükten sonra gülümseyerek, yanındakilere "Baylar, çocuklarımı nasıl buldunuz?" dedi. ${ }^{19}$

Dolayısıyla denilebilir ki, yarının büyüklerini, Türkiye Cumhuriyeti'nin gelecekteki sahiplerinin yetişmelerini izlemek onlarla sohbet etmek, Atatürk'e büyük keyif vermiştir. Bu bağlamda bir gün, Çankaya sırtlarında dolaşmaya çıkan Ata, küçük bir çocuğa rastlar. Adını ve okula gidip gitmediğini sorar. Adının Cemil olduğunu öğrendiği çocuğa bu kez Atatürk, "Ben kimim?" sorusunu yöneltir ve "Siz Gazi Paşasınız" cevabını alır. Bunun üzerine Atatürk gülümser ve "Beni benzetmiş olmayasın" der. Çocuk, "Hayır iyi biliyorum, çünkü bu dünyada kimse size benzemez" yanıtını verir. Büyüdüğün zaman ne olacaksın sorusuna, asker olup, düşman bu topraklara bir daha ayak basacak olursa, onu kovacağını söyleyen Cemil'in alnına bir öpücük koyan Atatürk, yoluna devam ederken, "Ulusun bağrından temiz bir kuşak yetişiyor. Bu eseri, onlara bırakacağım, gözüm arkada kalmayacak" der. ${ }^{20} \mathrm{Bu}$ olay, Ata'nın çocuklara ve gençlere güven ve inancını gösteren örneklerden yalnızca biridir.

Yine bir akşam Ata'ya nazı geçenlerden biri, "Düşünmelisiniz ki, eğer ölürseniz; heykelinizi paramparça ederler. Yaptıklarınızın hiçbiri ayakta kalmaz, çok yaşamaya bakmalısınız" demişti. Bunun üzerine Atatürk gülüp, "Unutmayınız ki Mustafa Kemaller yirmi yaşındadır" demiştir. ${ }^{21}$

${ }^{18}$ Sönmez, a.g.e, s.113.

${ }^{19}$ Süleyman Karagöz, Atatürk ve Çocuklar, Ankara, 1997, s.9-13.

20 Ercüment E.Talü, "Atatürk Çocukları Çok Severdi"; içinde Atatürk ve Çocuklar (1997), Süleyman Karagöz, s.14.

${ }^{21}$ Karagöz, a.g.e, s.21. 
Ulu Öndere göre, bugünün küçüğü, yarının büyüğüdür. Bugünün çocuk ve gençleri yarınlarımıza, geleceğimize yön vereceklerdir. Bugün bir hiç gibi görünen çocuk, belki yarının en dikkate değer ismi, en büyük kahramanı olacaktır.

Atatürk için çocuk öncelikle yarınlarımız demektir. Çocuk sevgisinin insan için bir ihtiyaç olduğunu, hele yaş ilerledikçe bu ihtiyacın kendisini daha kuvvetle hissettirdiğini belirten Atatürk'e göre, çocukları severiz. Çünkü çocuk, bizim devamımızdır. Her çocukta biz, sonsuzluğa doğru uzanıp gitme isteğinin doyumunu buluruz. ${ }^{22}$

Atatürk düşüncesinin temellerini oluşturan ilkelerden biri, tarihin bir ilerleme olduğu düşüncesidir. İlerleme düşüncesi de, dinamik devrim ideali de geleceğe yönelik olacaktır. ${ }^{23}$ Geleceğimiz ise çocuklarımız ve gençlerimizdir. Bu durumda çocuklarımızın ve gençlerimizin yarınlara gereği gibi hazırlanması, çağın gereklerine uygun bir eğitim görmeleri temel amacımız olmalıdır.

$\mathrm{Bu}$ sebeple Cumhuriyetin Milli Eğitim politikalarının esas amacının “Türk Milletini medeniyet safında en ileriye götürmek ve genç nesilleri Türk Milletini yüceltecek şekilde aşk, irade ve kudretle yetiştirmek; onları milli, medeni, insani fikir ve hislerle donatmak" ${ }^{4}$ olarak belirlendiği görülür.

Dünyadaki gelişmeleri yakından izleyen Atatürk, donmuş düşünceler ve inançlar yüzünden gelişen dünyaya ayak uyduramamayı temel problem olarak görüyordu. O, Osmanlının geri kalmasında eğitim kurumlarının zamanın şartlarına göre düzenlenememesinin etkisini dile getirerek Sakarya Savaşı yıllarında öğretmenlere şöyle sesleniyordu: "Şimdiye kadar takip olunan tahsil ve terbiye usullerinin milletimizin tarihî tedenniyatında en mühim bir âmil olduğu kanaatindeyim. Onun için bir milli terbiye programından bahsederken eski devrin hurâfâtından ve evsâf-ı fitriyemizle hiç de münasebeti olmayan yabancı fikirlerden, şarktan ve garptan gelebilen bi'lcümle tesirlerden tamamen uzak, seciye-i millîye ve tarihiyemizle mütenasip bir kültür kastediyorum. Millî dehâmızın inkişâfı ancak böyle bir kültür ile kâbildir." 25

Çağın gereklerini ve toplumun gereksinmelerini karşılamaktan uzak, yaratıcılı̆̆ı engelleyici yöntemleri olan geleneksel eğitim, ezberciliğe dayanıyor, bu ise yaratıcı yeni kuşakların yetişmesini engelliyordu. Geleneksel eğitim, biçim, içerik ve öz yönünden millî olmadığı gibi, bilimsel düşünceden de uzaktı.

\footnotetext{
${ }^{22}$ Sönmez, a.g.e, s.200, 204

${ }^{23}$ Sönmez, a.g.e, s.VII.

${ }^{24}$ Kemalist Eğitimin Tarih Dersleri (1931-1941), Tarih IV, 2004, s.266.

${ }^{25}$ Atatürk’ün Söylev ve Demeçleri I-III, Ankara, 1997, s.19-20.
} 
Atatürk, gerçek bir kurtuluşun ancak eğitimle sağlanacağını düşünüyor ve "terbiyedir ki, bir milleti ya hür, müstakil, şanlı, âli bir hey'et-i içtimâiye halinde yaşatır, ya bir milleti esaret ve sefâlete terk eder"26 diyordu.

Ulu Önderin eğitimde hassasiyetle üzerinde durduğu hususlardan biri millîlik ilkesi, bir diğeri bilimsellik ilkesi olmuştur. Eğitimde millîlik ilkesi, çocuk ve gençlere bir insan topluluğunu millet yapan değer ve inançların millî kültürün kazandırılması esasına dayanmıştır. "Türkiye Cumhuriyetinin temeli kültürdür"27 diyen Atatürk'e göre, kültür, okumak, anlamak, görebilmek, görebildiğinden mânâ çıkarmak, uyanık davranmak, düşünmek, zekâyı terbiye etmektir.

İnsanın düşünsel ve zihinsel gelişim özelliklerini, kavrayış yeteneğini kültür kapsamında değerlendiren Atatürk, yalnız düşünce hayatını değil, insanın, bunun dışındaki diğer eylem ve etkinliklerini, gündelik yaşam pratiklerini de kültürle ilişkili görür. Bir başka deyişle, kültürü, insan eylem ve etkinliklerinin yani dinamizminin ifadesi olarak kabul eder. ${ }^{28}$

Temelinde, dinamizm ve gelişimin bulunduğu böyle bir kültür anlayışında, akıl ve bilimin ön plana çıktığı açıkça görülmektedir.

Atatürk, Batı uygarlığının gelişmişliğinin ve dinamizminin kaynağını bilimden ve bilimin gelişme yeteneğinden aldığını düşündüğü için, bilime dayanmayan bir uygarlığın, Batı ile rekâbet edemeyeceğini belirtir. Bu sebeple "dünyada her şey için, medeniyet için, hayat için, muvaffakiyet için en hakiki mürşit ilimdir, fendir. İlim ve fennin haricinde mürşit aramak gaflettir, cehalettir, dalâlettir. Yalnız; ilmin ve fennin yaşadı̆̆ımız her dakikadaki safhalarının tekâmülünü idrâk etmek ve terakkiyâtını zamanla takip eylemek şarttır."29 Aksi taktirde bu gelişim ve değişimlere uyum sağlayamayan binlerce yıl öncesinin bilim ve tekniğini bugün aynen uygulamaya çalışan milletlerin başarı elde edemeyeceği açıktır. "Medenî olmayan insanlar, medenî olanların ayakları altında kalmaya maruzdurlar.,"30

O halde,

"Medeniyet yolunda yürümek ve başarıll olmak, hayatın şartıdır. Bu yol üzerinde duraksayanlar veyahut bu yol üzerinde ileri değil geriye bakmak cahilliği ve tedbirsizliğinde bulunanlar, medeniyetin coşkun seli altında boğulmaya mahkûmdurlar. Medeniyet yolunda başarı, yenileşmeye bă̆lıdır. Sosyal hayatta,

\footnotetext{
${ }^{26}$ A.g.e., C.II., s. 206

${ }^{27}$ A. Afet İnan, M. Kemal Atatürk'ten Yazdiklarım, Ankara, 1981, s.43.

28 Tayyip Duman, "Atatürk'ün Kültür ve Eğitim Anlayışı", Cumhuriyetin İlk Yıllarından Günümüze Dil, Kültü̈r, Eğitim, 2007, s.214-215.

${ }^{29}$ Atatürk'ün Söylev ve Demeçleri I-III, C.II, s.202.

${ }^{30}$ A.g.e., C.II, s. 234.
} 
ekonomik hayatta, ilim ve fen sahasında başarılı olmak için tek gelişme ve ilerleme yolu budur. Hayat ve geçime egemen olan kuralların zaman ile değişme, gelişme ve yenilenmesi zorunludur. Medeniyetin buluşlarının, tekniğin harikalarının dünyayı değişiklikten değiş̧ikliğe uğrattığı bir devirde, asırlık köhne zihniyetlerle geçmişe bağlılıkla varlı̆̆ın korunması mümkün değildir." ${ }^{11}$

Öyleyse, çağdaş dünyada, ulusumuzun hak ettiği yeri alabilmesi için, millî külttürümüze yabancılaşmadan, millî kültürümüzü çağdaş uygarlık seviyesinin üzerine çıkarmak esastır.

Çağdaşlaşmanın öz benliğimizi koruyarak gerçekleştirilmesi gerektiğini Atatürk, "Dünyanın bize hürmet göstermesini istiyorsak evvelâ bizim kendi benliğimize ve milliyetimize bu hürmeti hissen, fikren, fiilen, bütün ef'âl ve harekâtımızla gösterelim; bilelim ki, millî benliğini bulmayan milletler başka milletlerin şikârıdı""32 sözleriyle dile getirmiştir.

Milletimizin dehâsının gelişmesi ve bu sayede lâyık olduğu medeniyet düzeyine ulaşması şüphesiz, yüksek meslekler erbâbını yetiştirmek ve milli kültürümüzü yükseltmekle mümkün olabilecektir.

O halde çağdaş dünyada hak ettiğimiz yeri alabilmek için tek bir şeye ihtiyacımız vardır o da çalışkan olmaktır.

Böylece Atatürk'ün, Türk Ulusunu çağdaş uygarlık seviyesi ötesine ulaştırmayı arzulayan eğitim politikası, öğretim birliği temelinde millı̂, laik, bilimsel, yaygın bir eğitimi esas almış ulusal egemenlik ve bağımsızlığımızı koruyacak bir neslin yetiştirilmesini amaçlamıştır.

Kültüre dinamik bir nitelik kazandıran Atatürk'ün, kültürümüzü çağdaş uygarlık düzeyinin üzerine çıkarmayı hedeflerken 'en büyük eserim' dediği Cumhuriyetin temeline kültürü koyması ve onu da Türk gençliğine emanet etmesi gayet anlamlidir.

$\mathrm{Bu}$ durumda, Cumhuriyet sürekli bir devinim, yenilenme, atılım, araştırma demektir. Cumhuriyetin özünde adeta bir çocuk ruhu vardır. $\mathrm{Bu}$ sebeple, onun içinde taşıdığ 1 dinamik, taze ve yaratıcı çocuk ruhunu yitirmeden, o ruha uygun bir biçimde yorumlanması, düşüncede, bilimde, sanatta, olgun çocuk ruhu ile yaratıcı ürünler ortaya konulması, her dem taze ve keşfedici olma özelliğinin korunması gerekir. ${ }^{33}$

Zira Atatürk'e göre, bir millet ki resim yapmaz, bir millet ki heykel yapmaz, bir millet ki, fennin icabettirdiği şeyleri yapmaz; itiraf etmeli ki, o

\footnotetext{
${ }^{31}$ Atatürk'ün Söylev ve Demeçleri I-III, C.II, s.187.

${ }^{32}$ A.g.e., C.II, s. 147.

${ }^{33}$ İnam, a.g.e, s. 20.
} 
milletin tarik-i terakkide yeri yoktur. Hâlbuki bizim milletimiz, evsâf-1 hakkiyesile mütemeddin ve müterakki olmaya lâyıktır ve olacaktır. ${ }^{34}$

$O$ halde, genç nesle düşen görev, Atatürk devrimi esasları doğrultusunda, kendi öz benliğine yabancılaşmadan, dünyadaki gelişmeleri yakından takip etmek; bilim, sanat ve düşünce alanında çocuk aktivitesi ve yaratıcılığıyla özgün ürünler ortaya koyabilmek; Cumhuriyet ruhunun sürekli bir atılım, sürekli bir yenilenme, sürekli araştırma gerektirdiğini gözden kaçırmamaktır.

\section{KAYNAKÇA}

Atatürk'ün Söylev ve Demeçleri I-III (1997), Ankara: Türk İnkılâp Enstitüsü Yayınları.

Duman, Tayyip (2007), “Atatürk'ün Kültür ve Eğitim Anlayışı”, Cumhuriyetin İlk Yıllarından Günümüze Dil, Kültür, Eğitim, Der.N.Güngör, s.211-228.

Gutek, Gerald L. (2001), Eğitime Felsefi ve İdeolojik Yaklaşımlar, (Çev. Nesrin Kale), Ankara: Ütopya Yay.

İnam, Ahmet (2003), “Atatürk ve Çocuk”, MPM Anahtar, s.20.

İnan, A. Afet (1981), M. Kemal Atatürk'ten Yazdlklarım, Ankara.

Karagöz, Süleyman (1997), Atatürk ve Çocuklar, Ankara: Karagöz Yay.

Kemalist Eğitimin Tarih Dersleri (1931-1941). (2004), Kaynak Yayınları.

Matthews, Gareth B. (2000), Çocukluk Felsefesi, (Çev.Emrah Çakmak), İstanbul: Gendaş Kültür.

Nietzsche, Friedrich (1984), Böyle Buyurdu Zerdüşt, (Çev.A. Turan Oflazoğlu), İstanbul: Cem Yayınevi.

Okay, Cüneyt (1998), Osmanlı Çocuk Hayatında Yenileşmeler, İstanbul.

Özden, Yüksel (2000), Öğrenme ve Ö̆gretme, Ankara: Pegem Yay.

Sakaoğlu, Necdet (2003), Osmanlı'dan Günümüze Eğitim Tarihi, İstanbul: Bilgi Üniversitesi Yay.

Soyak, Hasan R. (1965), Doğumundan Ölümüne Kadar Atatürk ve Atatürk'ün Hususiyetleri, İstanbul: Hayat Yay.

Sönmez, Cemil (2004), Atatürk'te Çocuk Sevgisi, Ankara: Atatürk Araştırma Merkezi.

\footnotetext{
${ }^{34}$ Atatürk'ün Söylev ve Demeçleri I-III, C.II, s.71.
} 
Şahin, Hülya (2000), “Atatürk’te Çocuk Sevgisi ve Atatürk Döneminde Çocuklara Yönelik Yapılan Çalışmalar”, Silahlı Kuvvetler Dergisi, S.366, s.231-247.

Talü, Ercüment E., "Atatürk Çocukları Çok Severdi”; içinde Atatürk ve Çocuklar (1997), Süleyman Karagöz, Ankara: Karagöz Yay.

Wyckoff, Jerry vd. (2002), Bă̆ırıp Çağırmadan ya da Dövmeden Çocuk Terbiyesi, (Çev.Ümit T. Sargüney), Ankara: HYB Yay. 